\title{
Human adipose tissue-derived mesenchymal stem cells and their extracellular vesicles modulate lipopolysaccharide activated human microglia
}

\author{
Marta Garcia-Contreras (10) ${ }^{1}$ and Avnesh S. Thakor ${ }^{1}$
}

\begin{abstract}
Neurodegenerative diseases (NDs), such as Alzheimer's disease (AD), are driven by neuroinflammation triggered by activated microglial cells; hence, the phenotypic regulation of these cells is an appealing target for intervention. Human adipose tissue-derived mesenchymal stem cells (hAD-MSCs) may be a potential therapeutic candidate to treat NDs given their immunomodulatory properties. Evidence suggests that the mechanism of action of hAD-MSCs is through their secretome, which includes secreted factors such as cytokines, chemokines, or growth factors as well as extracellular vesicles (EVs). Recently, EVs have emerged as important mediators in cell communication given, they can transfer proteins, lipids, and RNA species (i.e., miRNA, mRNA, and tRNAs) to modulate recipient cells. However, the therapeutic potential of hAD-MSCs and their secreted EVs has not been fully elucidated with respect to human microglia. In this study, we determined the therapeutic potential of different hAD-MSCs doses $(200,000,100,000$, and 50,000 cells) or their secreted EVs $(50,20$, or $10 \mu \mathrm{g} / \mathrm{ml}$ ), on human microglial cells (HMC3) that were activated by lipopolysaccharides (LPS). Upregulation of inducible nitric oxide synthase (iNOS), an activation marker of HMC3 cells, was prevented when they were cocultured with hAD-MSCs and EVs. Moreover, hAD-MSCs inhibited the secretion of proinflammatory factors, such as IL-6, IL-8, and MCP-1, while their secreted EVs promoted the expression of antiinflammatory mediators such as IL-10 or TIMP-1 in activated microglia. The present data therefore support a role for hAD-MSCs and their secreted EVs, as potential therapeutic candidates for the treatment of NDs.
\end{abstract}

\section{Introduction}

Microglia are the resident macrophages of the central nervous system (CNS) and participate in CNS homeostasis $^{1,2}$. In response to injury, microglia change their state/polarization from a classic M1 phenotype to an activated M2 phenotype; while the M1 phenotype is toxic to neurons by secreting proinflammatory cytokines and reactive oxygen and nitrogen species, the $\mathrm{M} 2$ phenotype secretes anti-inflammatory cytokines, has enhanced phagocytic activity, and releases neurotrophic factors ${ }^{2}$. Hence, persistent activation of M1 microglia has been associated with the initiation and progression of neurodegenerative

Correspondence: Avnesh S. Thakor (asthakor@stanford.edu)

${ }^{1}$ Interventional Regenerative Medicine and Imaging Laboratory, Department of Radiology, Stanford University, Palo Alto, CA 94304, USA

Edited by Dr Joern Steinert diseases (NDs), such as Alzheimer's disease (AD) $)^{3,4}$. Recent genome-wide association studies have found that $\mathrm{AD}$ risk loci are in, or near, genes that are preferentially or uniquely expressed in microglia ${ }^{5}$. Taken together, these data strongly support the involvement of microglia in the early steps of $\mathrm{AD}$ thereby making them an important potential therapeutic target. Indeed, inhibiting proinflammatory M1 microglia and facilitating their switch to a protective and anti-inflammatory M2 phenotype may prove to be an important therapeutic strategy for treating neuroinflammatory-related diseases such as AD.

Mesenchymal stem cells (MSCs) are multipotent stem cells that have been shown to exert immunomodulatory properties $^{6-11}$, including immunosuppression of $\mathrm{T}$ lymphocytes and dendritic cells ${ }^{12}$, inhibition of B-cell proliferation ${ }^{13}$, and immunomodulation of other immune

\section{(c) The Author(s) 2021}

(c) (i) Open Access This article is licensed under a Creative Commons Attribution 4.0 International License, which permits use, sharing, adaptation, distribution and reproduction cc) in any medium or format, as long as you give appropriate credit to the original author(s) and the source, provide a link to the Creative Commons license, and indicate if changes were made. The images or other third party material in this article are included in the article's Creative Commons license, unless indicated otherwise in a credit line to the material. If material is not included in the article's Creative Commons license and your intended use is not permitted by statutory regulation or exceeds the permitted use, you will need to obtain permission directly from the copyright holder. To view a copy of this license, visit http://creativecommons.org/licenses/by/4.0/. 
cells such as natural killer cells ${ }^{14}$. Human adipose tissuederived MSCs (hAD-MSCs) are particularly promising for clinical therapy given they can be easily and repeatable harvested from patients using minimally invasive techniques $^{15}$. In animal models and clinical trials associated with $\mathrm{AD}, \mathrm{hAD}-\mathrm{MSCs}$ have shown to ameliorate AD disease symptoms by modulating inflammatory mediators as well as microglia proliferation, polarization, and phagocytic activity $^{16-18}$. The mechanism underlying this effect has been shown, in part, to be due to the paracrine activity of MSCs via their secretome, which includes their release of soluble cytokines, growth factors, and extracellular vesicles $(E V s)^{19,20}$. EVs are secreted small $(\sim 30-200 \mathrm{~nm}$ in diameter) lipid vesicles that have emerged as important mediators in intercellular communication by transferring RNA, DNA, proteins, and lipids between cells ${ }^{21,22}$. Furthermore, MSC-secreted EVs have been shown to have similar therapeutic properties when compared to their parent MSCs and recent studies have shown that EVs can also polarize microglia from an M1 to an M2 phenotype ${ }^{23}$. Given that EVs have a low immunogenicity, they therefore hold great potential as a potential cell-free therapy ${ }^{24,25}$.

To our knowledge, few studies have investigated the underlying mechanism of hAD-MSCs and their secreted EVs, in human microglia by focusing on their immunomodulatory phenotype. Given that the genomic responses in mouse models of inflammation do not correlate well with human genomic changes ${ }^{26}$ (i.e., molecular pathways and signaling functions differ between rodent and human microglia ${ }^{1}$ ), we investigated the effect of hAD-MSCs and their EVs, in a human microglia cell line (human microglia clone 3 (HMC3) cells) ${ }^{27,28}$.

\section{Results}

The effect of lipopolysaccharides (LPS) on HMC3 cells

To assess the effect of different magnitudes of toll-like receptor 4 (TLR4) activation, HMC3 cells were incubated with increasing concentrations $(0.01-10 \mu \mathrm{g} / \mathrm{ml})$ of LPS for $24 \mathrm{~h}$. At low concentrations of LPS, HMC3 cells had an ameboid spherical morphology, characteristic of activated microglia (Fig. 1A, B). Furthermore, LPS increased the expression of CD11b (Fig. 1B), a beta-integrin marker of microglia. While at low concentrations $(0.1-1 \mu \mathrm{g} / \mathrm{ml})$ of LPS there was microglia activation, higher concentrations $(10 \mu \mathrm{g} / \mathrm{ml})$ caused cell death $(p<0.01)$ (Fig. $1 B)$. Our data show that LPS-induced intracellular reactive oxygen species (ROS) accumulation even at lower concentrations $\leq 1 \mu \mathrm{g} / \mathrm{ml}$ (Fig. 1D). To further understand the effect of inflammation on HMC3 cells, the relative expression of cytokines and chemokines in the conditioned media from $1 \mu \mathrm{g} / \mathrm{ml}$ LPS-treated and control cells was measured (Fig. 1E, F); here, monocyte chemoattractant protein-1 (MCP-1), brain-derived neurotrophic factor (BDNF), TIMP metallopeptidase inhibitor 1
(TIMP-1), interleukin 6 (IL-6), and IL-8 were all increased upon LPS activation.

\section{Characterization of hAD-MSCs and their secreted EVs}

hAD-MSCs were isolated using Lipogems ${ }^{\circledR}$ technology which is a nonenzymatic method for AD-MSC isolation as previously described $^{29}$. Three different concentrations of hAD-MSCs $(200,000,100,000$, and 50,000 cells) were cultured and their morphological features assessed after $24 \mathrm{~h}$ by phase-contrast microscopy (Fig. 2A). Representative images show that hAD-MSCs had the typical MSC spindle and multipolar shape morphology. To determine the role of secreted EVs by hAD-MSCs, we collected the conditioned media and EVs. Expression of EV markers in the fractionated vesicles and conditioned medium were also evaluated (Fig. 2B). Western blot analysis demonstrated enrichment of CD63 (i.e., a classical EV marker) in both isolated EVs and the CM when compared to cell lysates. Ponceau red staining show total protein content.

Analysis of the secretome from hAD-MSCs (Fig. 2C-E) showed an increased expression of TIMP-1, IL-6, and IL8; indeed, these cytokines were highly expressed in EVs when compared to parental MSCs (Fig. 2D, E).

\section{Coculture of HMC3 cells with hAD-MSC or their secreted EVs}

Untreated and activated ( $1 \mu \mathrm{g} / \mathrm{ml}$ LPS) HMC3 cells were cocultured with different ratios of hAD-MSCs and EVs for 24h (Fig. 3A). When untreated HMC3 cells were cocultured with hAD-MSCs, they showed a typical resting morphology of elongated and ramified microglia, similar to our control experiment (Fig. 1A). While the addition of LPS $(1 \mu \mathrm{g} / \mathrm{ml})$ resulted in HMC3 cells forming an ameboid spherical morphology, coculturing with hAD-MSCs at 200,000 and 100,000 cells (Fig. 3B) or EVs at 20 and $10 \mu \mathrm{g} / \mathrm{ml}$ (Fig. 3C) showed a significant decrease in the amount of ameboid cells. In addition, images from the Celigo image cytometer revealed colocalization (yellow) of CellBrite Orange labeled isolated EVs by CellBrite Green labeled HMC3 cells.

\section{Characterization of activated HMC3 cells following coculture with hAD-MSCs or their secreted EVs}

To investigate the effects on microglia phenotype polarization, HMC3 cells were activated with $1 \mu \mathrm{g} / \mathrm{ml}$ LPS for $24 \mathrm{~h}$ and then cocultured with hAD-MSCs or their secreted EVs. We performed an immunofluorescence staining for CD11b, a marker of beta-integrin on microglia and phalloidin, which detects F-actin (Fig. 4A). As previously shown, LPS-treatment upregulated CD11b expression and ameboid morphology in comparison to untreated HMC3 cells. However, when activated microglia were cocultured with hAD-MSCs or their EVs, there 


\section{A}

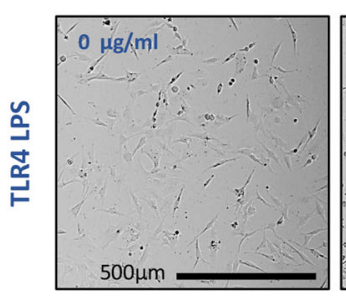

B
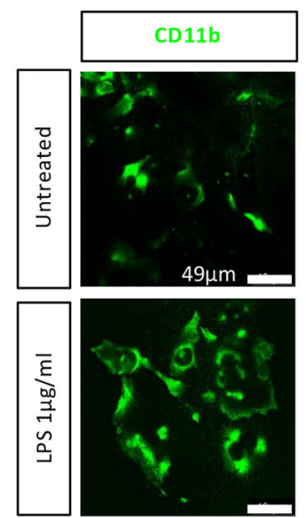

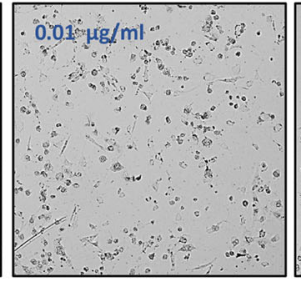

$0.1 \mu \mathrm{g} / \mathrm{mal}^{8}$
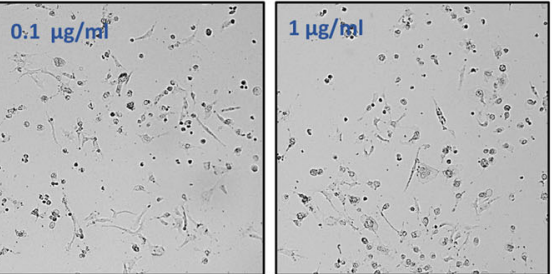

C
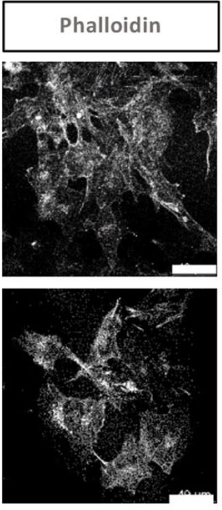

D
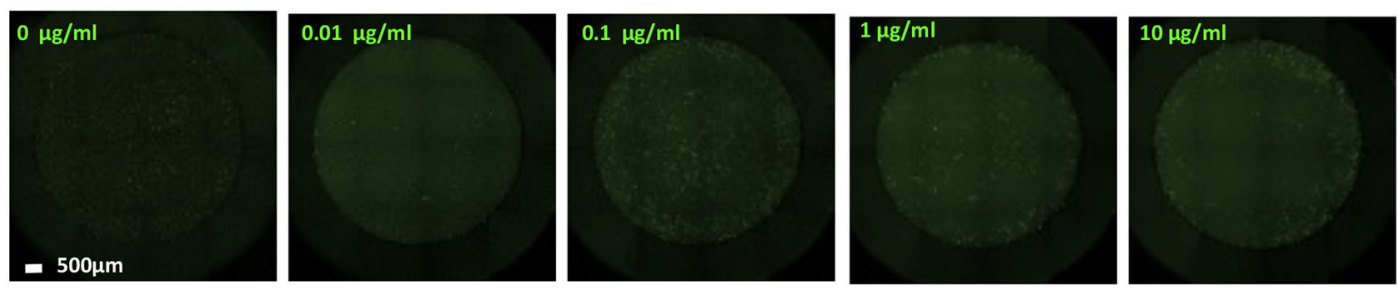

E

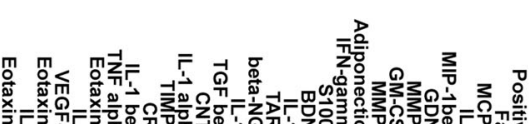

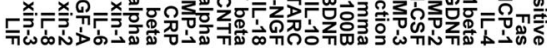

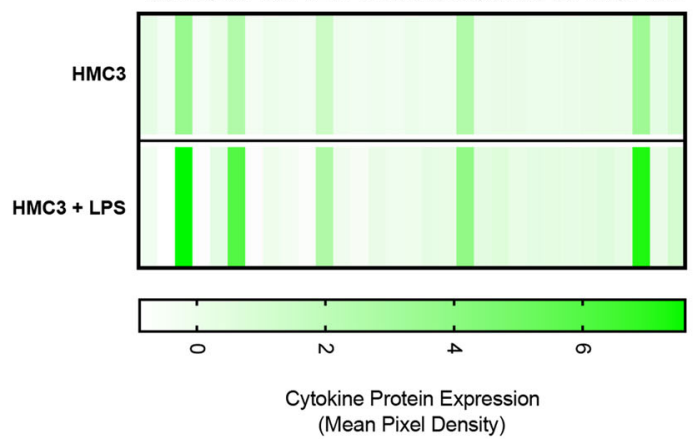

$\mathbf{F}$
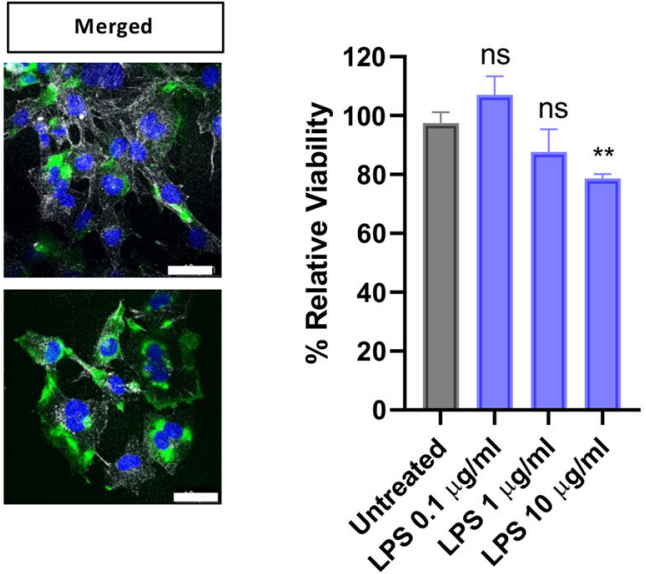

- $\mathrm{HMC3}$

- $H M C 3+$ LPS

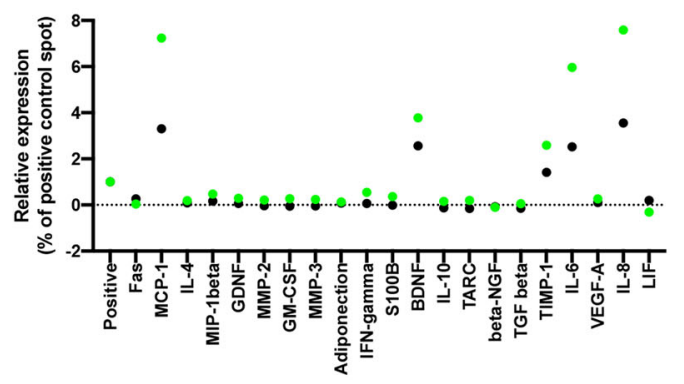

Fig. 1 (See legend on next page.) 
(see figure on previous page)

Fig. 1 Effects of LPS on HMC3 microglia. A Representative phase-contrast images show morphological changes in HMC3 microglia after $24 \mathrm{~h}$ incubation with different doses of LPS. Scale bar, $500 \mu \mathrm{m}$. B Immunofluorescence staining for CD11b (green fluorescent signal), phalloidin (white), and nuclear DAPI staining (blue) was performed. Scale bar, $49 \mu \mathrm{m}$. C Cell viability after $24 \mathrm{~h}$ incubation with different doses of LPS was determined by the XTT assay. Values for each treatment are expressed as percentages of the corresponding control (cells untreated). The results shown are the mean \pm SEM of triplicates. Double asterisks (**) indicate a significant difference from the LPS-activated group vs control $(p<0.01)$. $\mathbf{D}$ LPS-induced ROS generation in HMC3 microglia cells in response to $24 \mathrm{~h}$ LPS exposure was determine using Celigo imaging cytometer. Representative images are shown. E Heat map showing relative cytokines expression. Collected supernatants were subject to cytokine array blots containing 30 different human neurologically relevant proteins. F Representation of relative cytokines expression. The values are shown as mean pixel density.

was a decrease in CD11b expression and ameboid morphology which was visible after $24 \mathrm{~h}$ (Fig. 4A).

Following LPS activation, the amount of inducible nitric oxide synthase (iNOS) in HMC3 cells significantly increased from 1.49 to 98.51 arbitrary units (Fig. 4B, C). On the contrary, in the presence of hAD-MSCs and hADMSC EVs, at all ratios, the level of iNOS was significantly decreased (Fig. 4C). Furthermore, we observed that labeled zymosan particles were phagocytosed by HMC3 cells treated with LPS (Fig. 5). However, this effect was inhibited when HMC3 cells were cocultured with hADMSCs, but not when they were cocultured with hADMSCs EVs.

\section{Cytokine secretion by activated HMC3 cells}

Cytokine secretion in HMC3 activated or nonactivated microglia in the presence or absence of hAD-MSCs or EVs was determined (Fig. 6A, B). Following LPS activation of HMC3 cells, there was a fourfold increase in IL- 6 and fivefold increase in IL-8 when compared to resting untreated microglia (Fig. 6C-F). Treatment with hADMSCs attenuated the secretion of IL-8, as well as IL-6 to a lesser degree, from activated microglia (Fig. 6C, E and Supplementary Fig. 1). In contrast, the secretion of IL-8 or IL-6 was upregulated in the presence of hAD-MSC EVs (Fig. 6D, F). Similarly, activation of HMC3 cells resulted in a twofold increase in MCP-1 which was decreased by both hAD-MSCs (50,000 cells) and hAD-MSCs EVs (50 and $20 \mu \mathrm{g} / \mathrm{ml}$ ), with the effect being greater for EVs (Fig. 6D, F and Supplementary Fig. 1). In addition, in activated microglia, the protein level of TIMP-1 was also significantly upregulated by EVs and downregulated by high hAD-MSCs doses (200,000 and 100,000 cells), while IL-10 levels were upregulated by higher doses of hAD-MSCs EVs $(50$ and $20 \mu \mathrm{g} / \mathrm{ml})$. BDNF protein expression was also upregulated by EVs and downregulated by all hAD-MSCs doses (Fig. 6E, F and Supplementary Fig. 2).

\section{Discussion}

Although previous studies have examined the neuroimmunomodulatory potential of MSCs and their secretome, in mouse microglia ${ }^{30,31}$, this is the first report demonstrating the therapeutic efficacy of hAD-MSCs and their EVs, on human microglia. Here, we show that hAD-
MSCs and their secreted EVs can modulate the phenotype of activated human microglia.

The therapeutic and regenerative potential of MSCs and their secretome have attracted much attention in recent years, especially for the treatment of neuroinflammatory and $\mathrm{NDs}^{32-34}$. MSCs are multipotent stromal cells which have been shown to have immunomodulatory properties, low tumorigenic risk, and are able to efficiently home to areas of injury ${ }^{32,35,36}$. Many studies have reported that MSCs exhibit their immunomodulatory function via EVs, which are secreted into their surrounding microenvironment $^{37-39}$. The use of MSC-secreted EVs could provide several advantages over parental MSCs, given they are less likely to cause pulmonary embolism following intravenous injection, have lower immunogenicity, and have been shown to cross the blood brain barrier ${ }^{25,40,41}$. Hence, in the present study, we tested both hAD-MSCs and their secreted EVs, on human microglia.

In order to activate HMC3 cells, we used the bacterial endotoxin LPS, which is the most commonly used ligand of TLR $4^{28,42}$. TLRs are a class of pattern-recognition receptors in the innate immune system, and TLR4 is a key regulator of inflammation that has been shown to play an essential role in NDs such as $\mathrm{AD}^{43,44}$. LPS was shown to increase ROS production in microglia and activate them to a classical "M1" proinflammatory phenotype; this was supported by their morphological change from a ramified to an ameboid shape with increased CD11b expression. In addition, LPS-activated microglia demonstrated an increase in expression of iNOS ${ }^{45}$, which has been associated with neuronal cell death and neurodegenerative conditions $^{46}$, as well as cytokines including MCP-1, IL-6, and IL-8, which have been shown to be present in chronic inflammatory diseases ${ }^{4-51}$.

Treating activated microglia with hAD-MSCs, or their secreted EVs, resulted in a decrease in CD11b expression and ameboid morphology as well as a decrease in expression of iNOS and MCP- ${ }^{31}$. It has been previously reported that nitric oxide signaling is involved in brain memory development through nNOS and neuroinflammation through iNOS which has also been shown to mediate several CNS inflammatory processes ${ }^{52}$. In relation to CNS diseases such as AD, it has been reported that $\mathrm{nNOS}$ and iNOS contribute to the progression of $\mathrm{AD}$, 
A

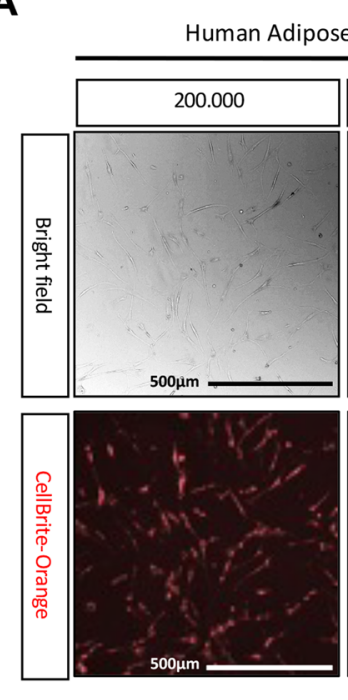

C

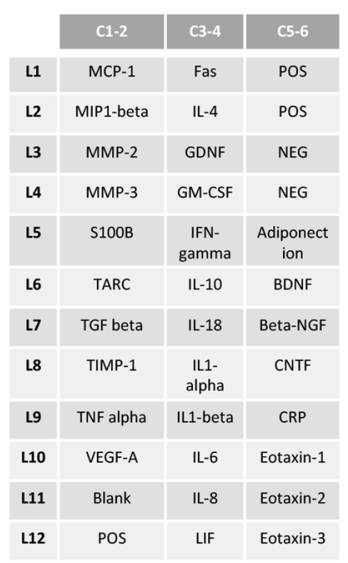

B
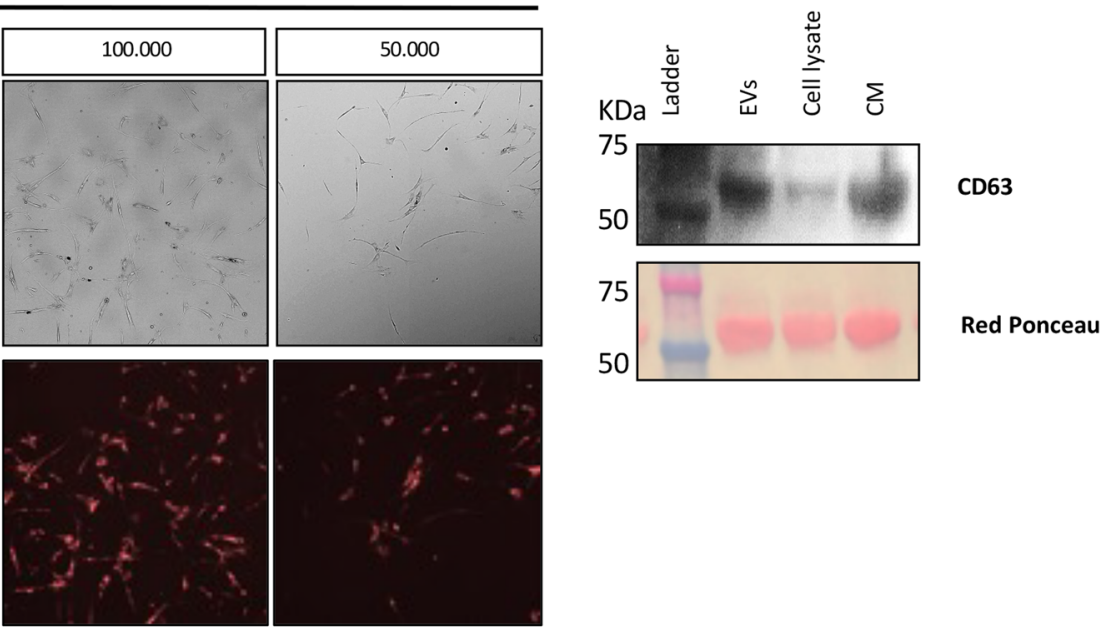

D

Human Adipose tissue -derived mesenchymal stem cells Extracellular Vesicles

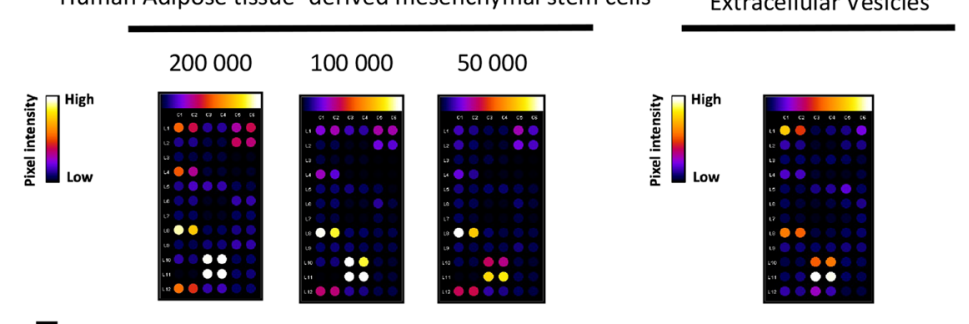

E
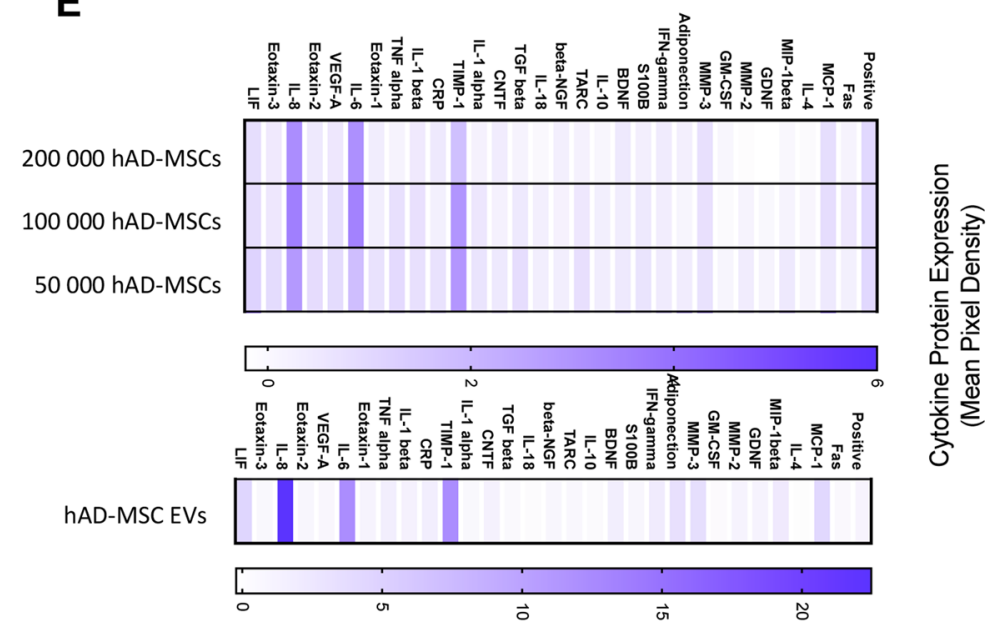

Fig. 2 Human adipose tissue-derived stem cells and extracellular vesicles characterization. A Morphology of isolated hAD-MSCs after $24 \mathrm{~h}$ in culture. Representative images are shown. B Western blotting was used to confirm the abundances of extracellular vesicle marker CD63 in isolated extracellular vesicles (EVs), cell culture supernatants (CM), and cell lysates. Ponceau red staining is representative of total protein content. C Gene map of cytokine array containing 30 different human neurologically relevant proteins; all spots are in duplicate and $\mathbf{D}$ cytokine array membranes. $\mathbf{E}$ Heat map showing relative cytokines expression. The values are shown as the mean pixel density.

with nNOS having a stronger effect ${ }^{53}$. Removal of iNOS in transgenic AD mice, or the use of iNOS inhibitors such as l-NAME (i.e., a general NOS inhibitor) or $1400 \mathrm{~W}$ (i.e., a specific iNOS inhibitor), results in improved behavioral dysfunction and protection against $A \beta$ neurotoxicity in models of $\mathrm{AD}^{53,54}$. Furthermore, the use of nNOS inhibitors has shown to be beneficial in other models of CNS diseases such as Parkinson's disease and ALS.

While hAD-MSCs decreased the expression of IL-6 and IL-8, their secreted EVs increased the level of these 


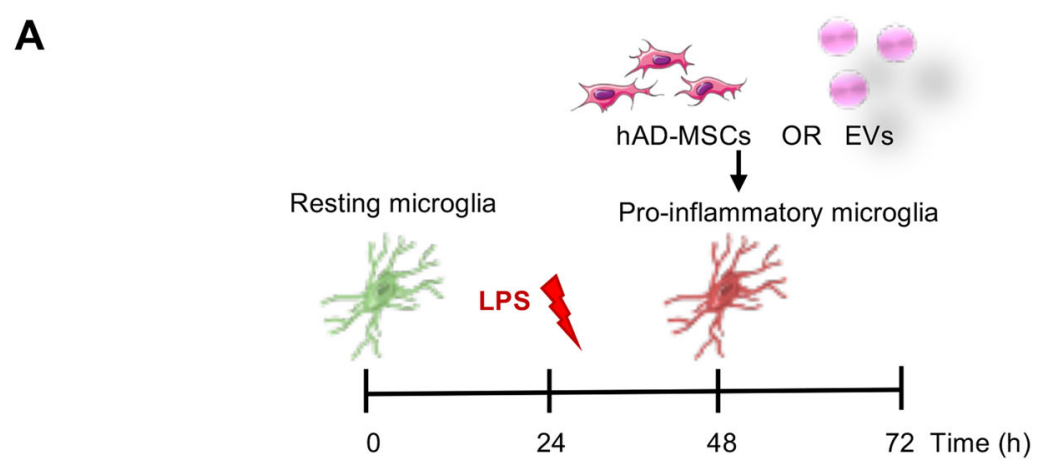

B Adipose tissue-derived Mesenchymal Stem Cells

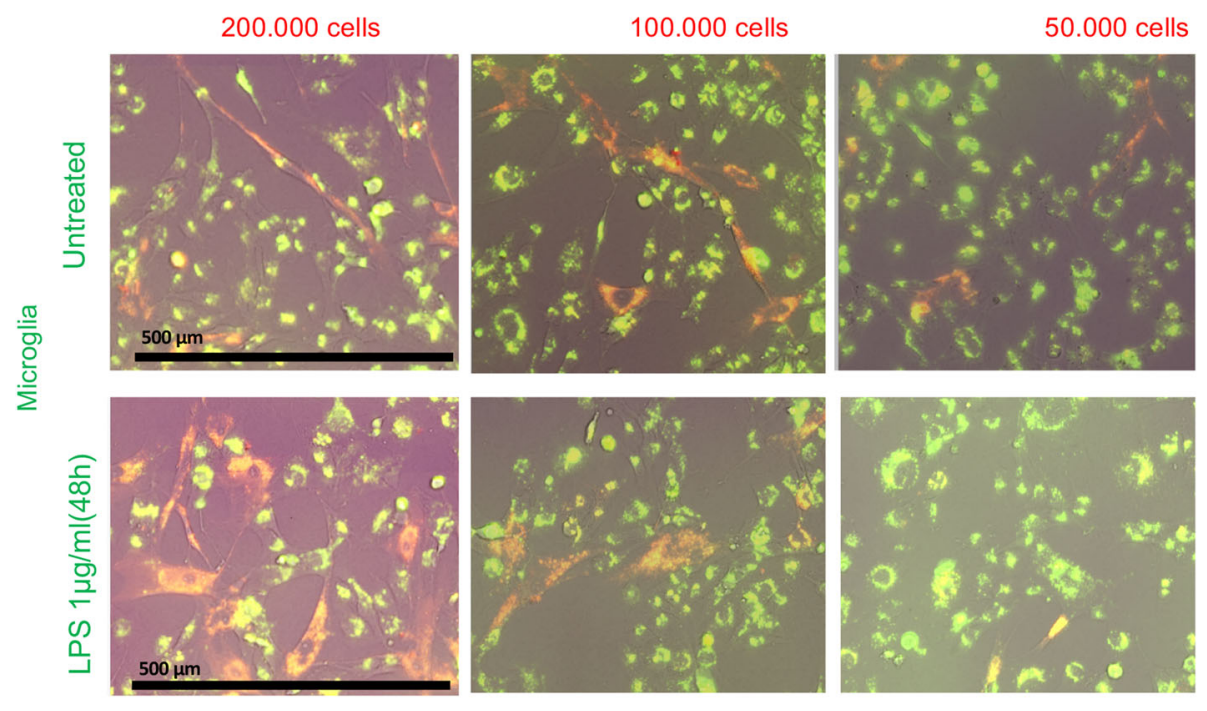

C Adipose tissue-derived Mesenchymal Stem Cell-derived Extracellular Vesicles

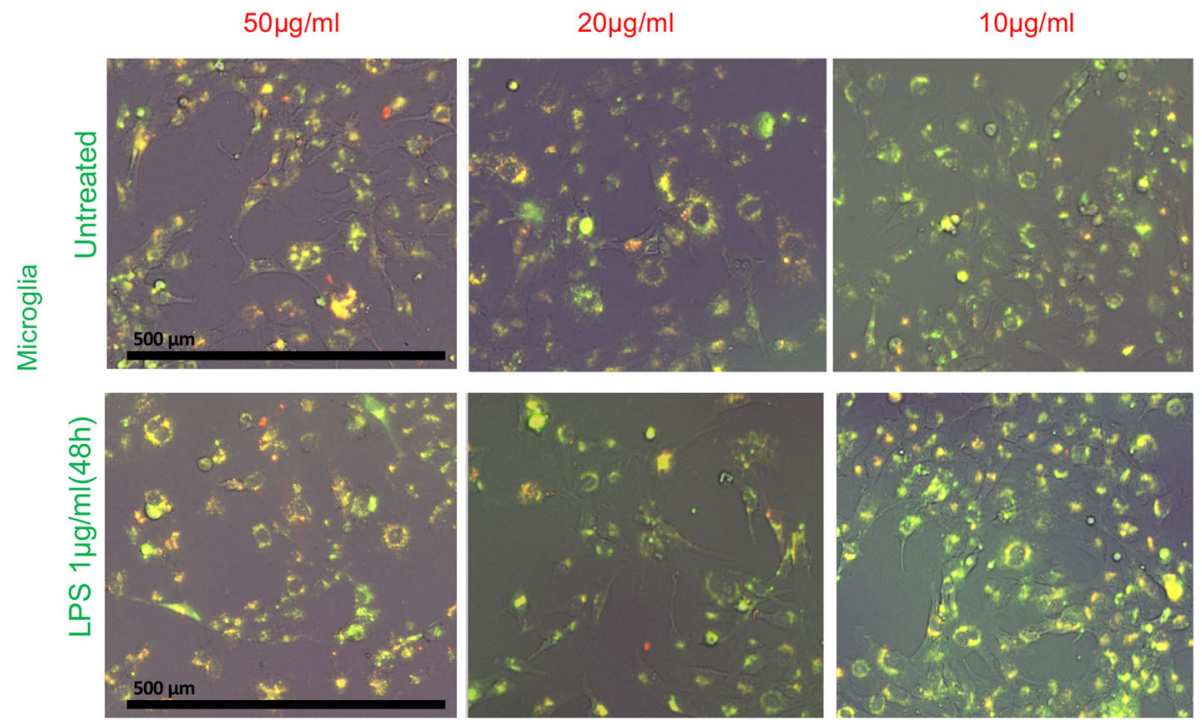

Fig. 3 Coculture of human HMC3 microglia cells and human adipose tissue-derived mesenchymal stem cells OR extracellular vesicles. A Schematic overview of the coculture protocol. B Fluorescence images of culture HMC3 microglia cells (green) and human adipose tissue-derived mesenchymal stem cells (red) in the presence or absence of $1 \mu \mathrm{g} / \mathrm{ml} \mathrm{LPS.} \mathrm{C} \mathrm{Fluorescence} \mathrm{images} \mathrm{of} \mathrm{culture} \mathrm{HMC3} \mathrm{microglia} \mathrm{cells} \mathrm{(green)} \mathrm{and} \mathrm{human}$ adipose tissue-derived mesenchymal stem cell extracellular vesicles (red) in the presence or absence of $1 \mu \mathrm{g} / \mathrm{ml}$ LPS. Scale bar $500 \mu \mathrm{m}$. 
A

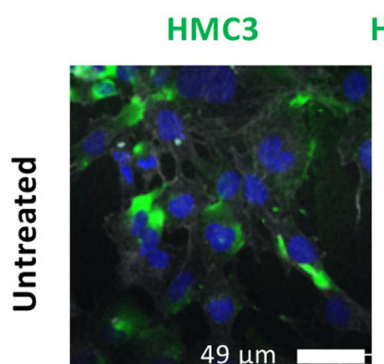

HMC3+hAD-MSC EVs

$\mathrm{HMC} 3+\mathrm{CM}$

HMC3+ hAD-MSCS
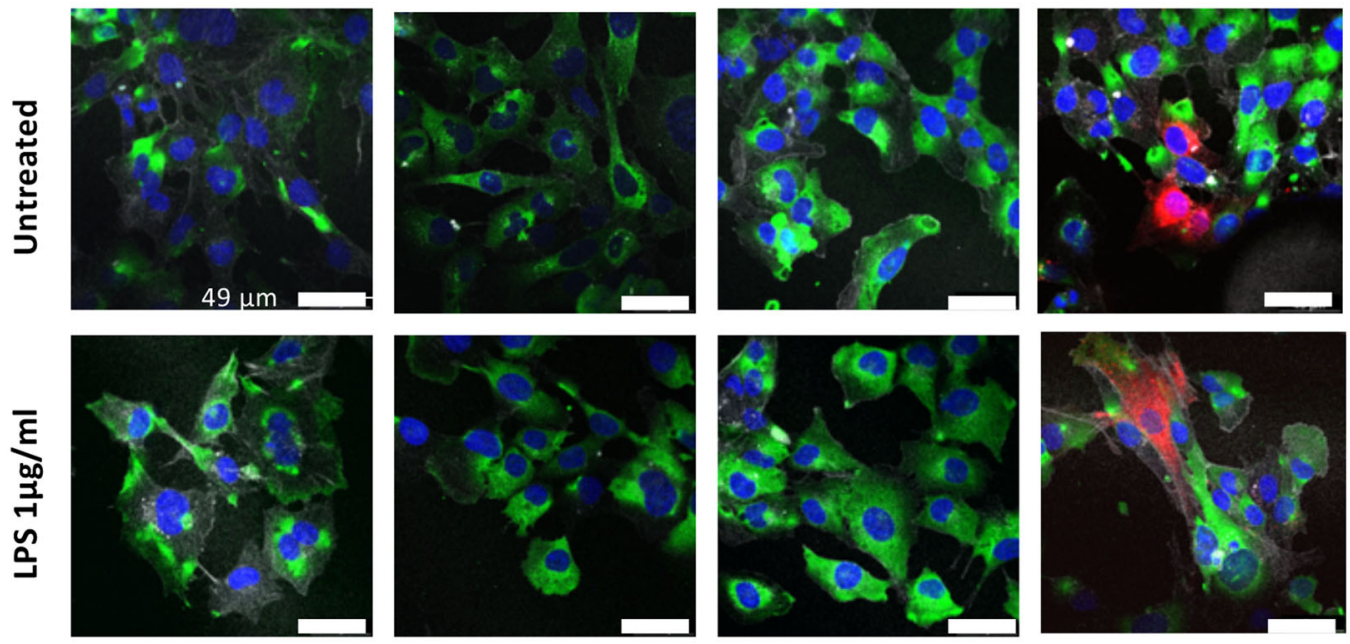

B
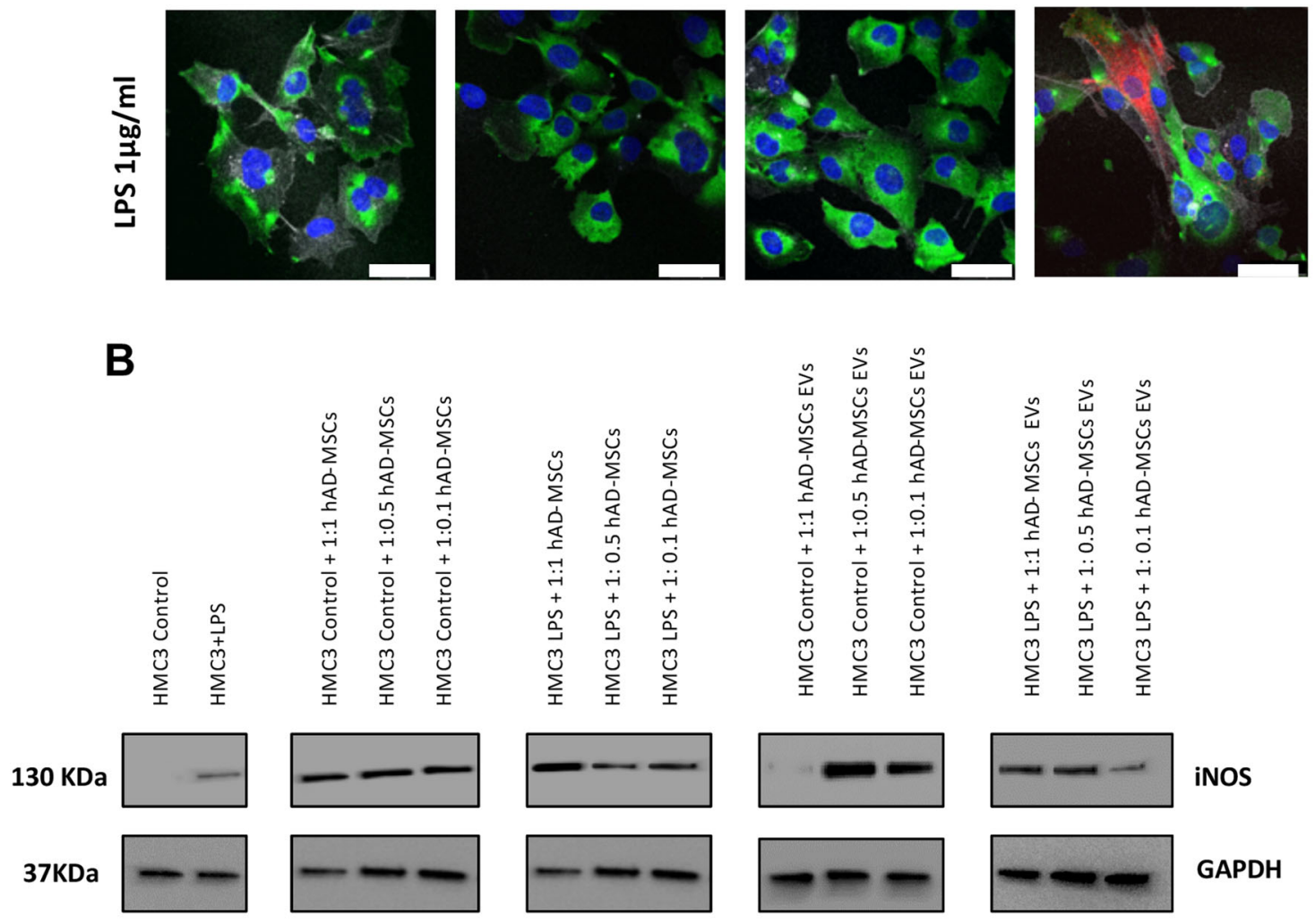

iNOS
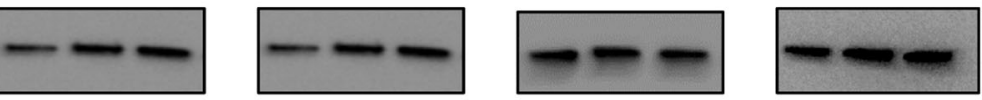

GAPDH

C

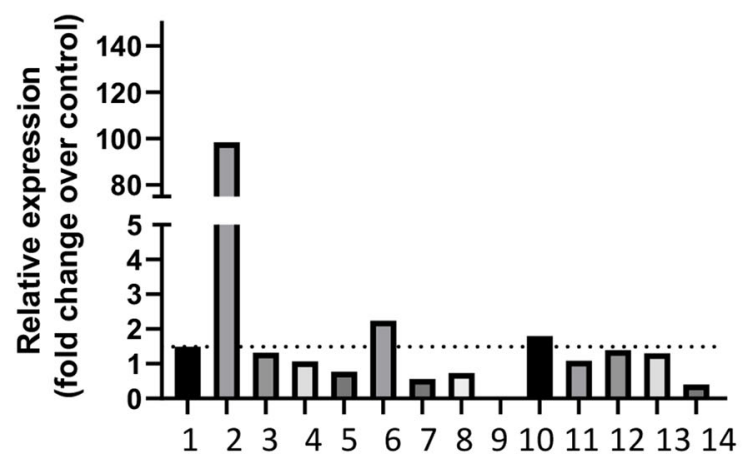

$1=$ Control

$2 \square$ LPS

$3 \square$ Control + 1:1 hAD-MSCs

4 Control + 1:0.5 hAD-MSCs

5 Control + 1:0.1 hAD-MSCs

6 LPS + 1:1 hAD-MSCs

7 LPS + 1:0.5 hAD-MSCs

8 LPS + 1:0.1 hAD-MSCs

$9 \square$ Control + 1:1 hAD-MSCs EVs

10 Control + 1:0.5 hAD-MSCs EVs

11 Control + 1:0.1 hAD-MSCs EVs

12 LPS + 1:1 hAD-MSCs EVs

13 口 LPS + 1:0.5 hAD-MSCs EVs

14 LPS + 1:0.1 hAD-MSCs EVs

Fig. 4 Effects of hAD-MSCs on microglia immunoinflammatory phenotype. A Immunofluorescence staining for M1 marker CD11b (green), Factin phalloidin (white), and DAPI (blue). hAD-MSCs are labeled with CellBrite Orange (red). B Proteins expression levels of inducible nitric oxide (iNOS). C Western blot quantification. iNOS inducible nitric oxide. 


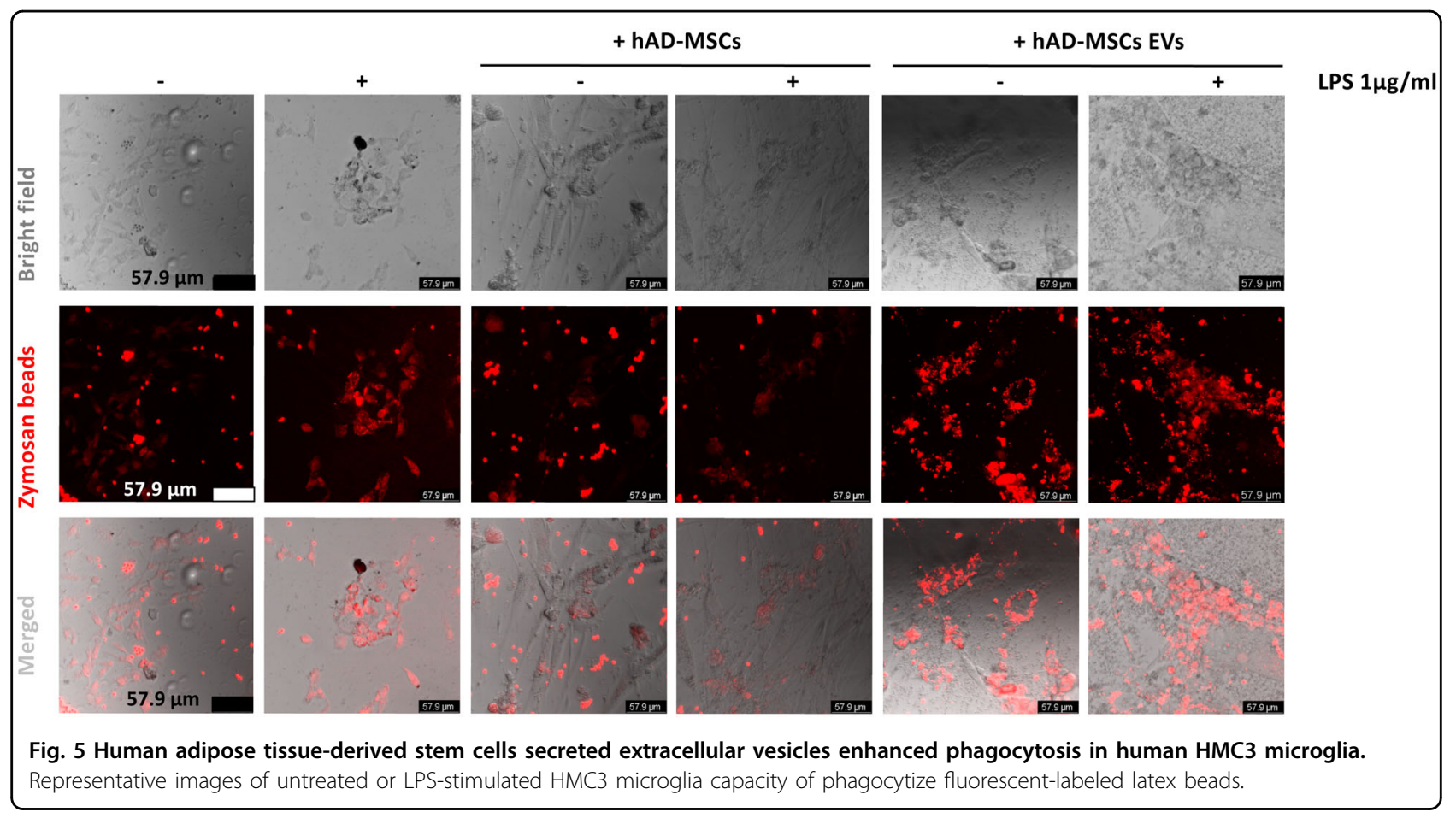

cytokines; this discrepancy can be partially explained by the fact that IL- 6 and IL- 8 are highly expressed in EVs and hence any increase in these levels might come from EVs rather than the microglia. Interestingly, hAD-MSCs only were also able to decrease the phagocytic capacity of activated microglia. Overall, our data suggest that hAD-MSCs and their secreted EVs are able to inhibit the proinflammatory effects of human microglia by inhibiting M1 polarization and promoting instead their M2 polarization.

Our results also show that hAD-MSCs increased the secretion of factors, such as TIMP-1, which is known to be a regulator of hAD-MSCs function and proliferation ${ }^{55,56}$ and leukemia inhibitory factor which maintains the stem state of $\mathrm{MSCs}^{57}$; both these factors were higher with a lower number of hAD-MSCs (i.e., 50,000 cells). In contrast, while IL-6, which mediates several therapeutic effects of hAD-MSCs ${ }^{58}$, increased in proportion to the number of hAD-MSCs, IL-8 did not change with the number of hAD-MSCs. Taken together, these results show that the number of hAD-MSCs is important when considering their therapeutic effects which will be important for their "dosing" as they are clinically translated.

Both IL-10 and TIMP-1 are important antiinflammatory mediators which act as negative-feedback regulators to maintain a balanced immune response. Indeed, IL-10 plays a crucial anti-inflammatory role in microglia ${ }^{59}$ and has been shown to be involved in the cognitive decline of Alzheimer patients, where slow decliners have higher levels of IL- $10^{60}$. In our study, hADMSC EVs $(50 \mu \mathrm{g} / \mathrm{ml})$ increased IL-10 levels which may represent an important neuroprotective effect. TIMP-1 is expressed by variety of cell types including astrocytes ${ }^{61}$, and is known to be able to shift microglia from an M1 to an M2 state ${ }^{62,63}$. In LPS-activated microglia cocultured with EVs, TIMP-1 was increased supporting an antiinflammatory role of EVs on microglia. BDNF, which is a neurotrophin that is required for the survival of specific neuronal populations given its ability to facilitate axonal and dendritic growth and synaptogenesis ${ }^{64,65}$, has also been shown to be associated with cognitive decline in AD patients, with levels decreasing in advanced stages ${ }^{66,67}$. Interestingly, EVs were able to increase the levels of BDNF in LPS-activated microglia which, in turn, may be beneficial for them to ameliorate neural dysfunction.

In conclusion, we demonstrate that hAD-MSCs and their secreted EVs can prevent a proinflammatory microglia phenotype. These findings support a role for hAD-MSC EVs as a potential cell-free therapy for the treatment of neuroinflammatory diseases including AD. Further studies are required to determine the content of hAD-MSC-secreted EVs and the different molecular mechanisms of their action to understand how they exactly modulate microglia both in cell culture as well as in animal models.

\section{Materials and methods}

Cell lines and culture

HMC3 cells were purchased from ATCC $\left(\right.$ ATCC $^{\circledR}$ CRL$3304^{\mathrm{TM}}$ ) and grown in EMEM Media (ATCC, VA, USA), supplemented with $10 \%$ fetal bovine serum (Gibco) and 


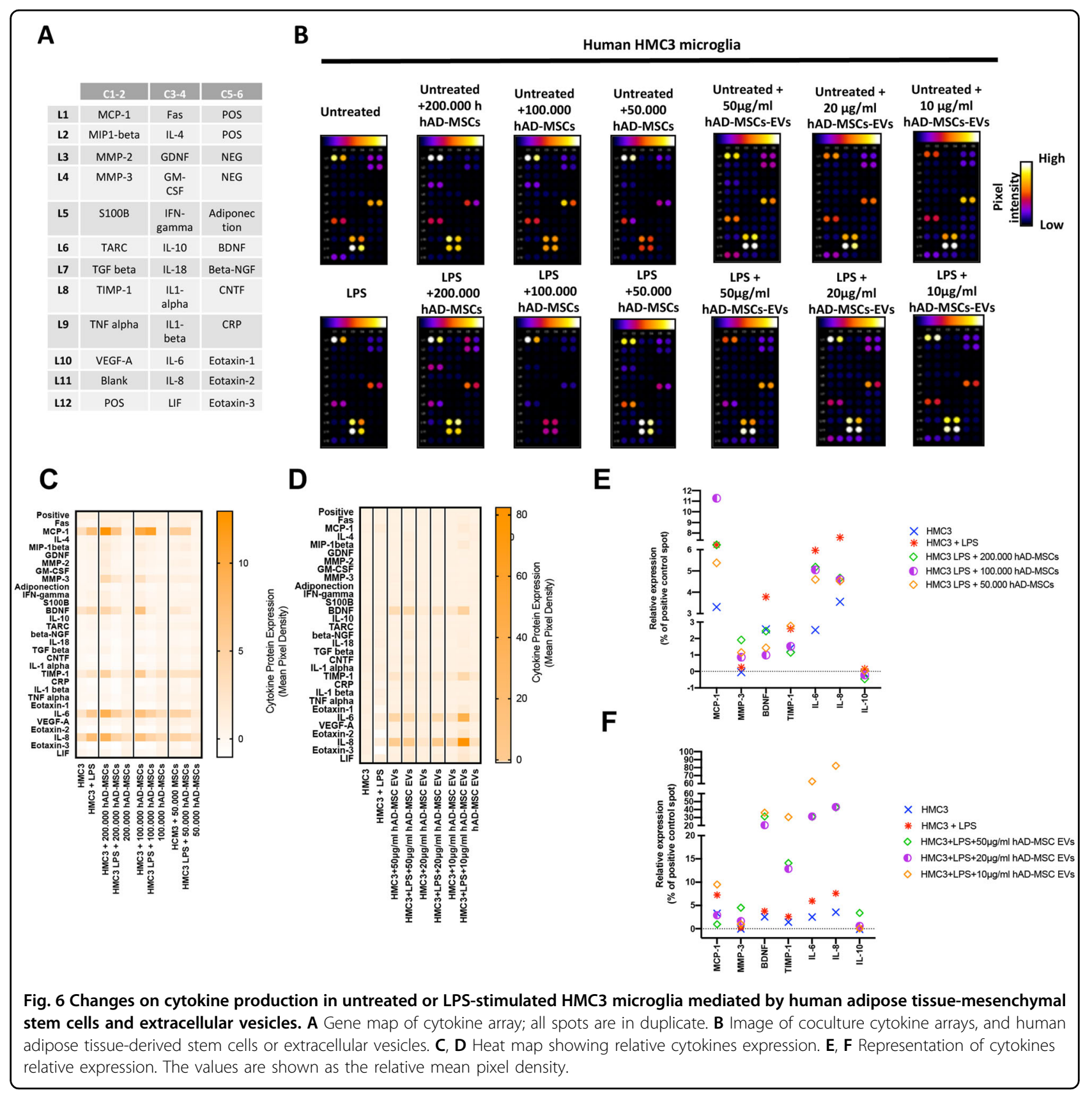

1\% penicillin/streptomycin (Gibco-Life Technologies, USA) in multilayer flasks (Nest Scientific, USA) at $37^{\circ} \mathrm{C}$ and $5 \% \mathrm{CO}_{2}$ in a forced air incubator. hAD-MSCs were kindly donated by Dr. Ricordi's Lab (Diabetes Research Institute, University of Miami, Miami, FL, USA); details of their isolation and characterization have been previously described $^{68,69}$. These cells were grown in Prime-XV expansion serum-free Media (91135, Fujifilm Irvine Scientific, CA, USA) and $1 \%$ penicillin/streptomycin (GibcoLife Technologies, USA) at $37^{\circ} \mathrm{C}$ and $5 \% \mathrm{CO}_{2}$ in a forced air incubator. For all experiments, hAD-MSCs were used up to passage number 5 .
Collection and characterization of hAD-MSC-secreted EVs hAD-MSCs were grown to $80-90 \%$ confluence, and then maintained in serum-free Prime-XV media (91135, Fujifilm Irvine Scientific, CA, USA) which was collected after $24 \mathrm{~h}$ and then centrifuged at $500 \times g$ for $5 \mathrm{~min}$ followed by $2000 \times g$ for $30 \mathrm{~min}$ at $4{ }^{\circ} \mathrm{C}$ to remove cell debris and large apoptotic bodies. The media were then filtered through a $0.45 \mu \mathrm{m}$ filter and stored. Next, a polyethylene glycol (PEG) solution was prepared to precipitate EVs. PEG with a molecular weight of 4000 (25322-68-3, Bioworld, $\mathrm{OH}, \mathrm{USA}$ ) was combined with filtered water and sodium chloride $(1 \mathrm{M})$ to make a twofold concentrated 
(2x) stock solution. The $2 \mathrm{x}$ stock solution was added to an equal volume of serum-free conditioned media. In order to isolate EVs, the collected media were added to an equal volume of a $2 \mathrm{x}$ PEG stock solution at $4{ }^{\circ} \mathrm{C}$. After the $2 \mathrm{x}$ PEG solution was added, samples were mixed thoroughly by inversion, and incubated at $4{ }^{\circ} \mathrm{C}$ overnight. The next day, samples were centrifuged in a tabletop centrifuge at $3000 \times g$ for $1 \mathrm{~h}$ at $4{ }^{\circ} \mathrm{C}$. Conical tubes were then decanted, and allowed to drain for $5 \mathrm{~min}$, tapping occasionally to remove excess PEG. The resulting pellet was suspended in $100 \mu \mathrm{l}$ of particle-free PBS (pH 7.4; Gibco-Life Technologies, USA) and the samples finally stored at $-80^{\circ} \mathrm{C}$. Prior to their use, the protein content in EVs was quantified using a BCA protein assay following the manufacturer's recommendations (Pierce, Thermo Scientific) after samples were lysed with RIPA buffer (89900, Pierce, Thermo Scientific) which was supplemented with a protease inhibitor mixture (11697498001, Sigma-Aldrich).

\section{Fluorescence labeling of HMC3 cells, hAD-MSCs, and their secreted EVs}

To enable discrimination between the different cell types and visualization of EVs, hAD-MSCs and their secreted EVs were stained with CellBrite Orange (30022, Biotium, CA, USA) and HMC3 cells were stained with CellBrite Green (30021, Biotium, CA, USA). In brief, all cells were detached from culture flasks by trypsinization and then quantified using a Countess II Automated Cell Counter (Invitrogen, Thermo Fisher) before being suspended at a density of $1 \times$ $10^{6}$ cells $/ \mathrm{ml}$ in cell culture media. For cell staining, $5 \mu \mathrm{l}$ of the CellBrite labeling solution was added per $1 \mathrm{ml}$ of cell suspension for $20 \mathrm{~min}$ at $37^{\circ} \mathrm{C}$. The mixture was then centrifuged at $350 \times g$ for $5 \mathrm{~min}$ to create a cell pellet and to enable the staining solution to be removed. The cells were then washed with PBS and placed in fresh media. For EVs, the pellets were resuspended in $100 \mu \mathrm{l}$ PBS (1x), mixed with $10 \mu \mathrm{l}$ Orange CellBrite solution, and incubated for $30 \mathrm{~min}$ at $37^{\circ} \mathrm{C}$. The labeling reaction was stop by adding $100 \mu \mathrm{l}$ of PEG (2x) stock solution and the EVs retrieved by centrifugation at $5000 \times g$ for $30 \mathrm{~min}$.

\section{Coculture experiments}

Microglia can be activated via TLRs, a class of patternrecognition receptors in the innate immune system. Microglial TLR 4 is a key regulator of inflammation that may play a role in $\mathrm{AD}^{43}$. Bacterial endotoxin LPS is the most commonly used ligand of TLR4 which can induce microglial activation. To asses if hAD-MSCs and their secreted EVs can modulate microglial activation in response to LPS, HMC3 cells were plated at 200,000 cells per well in six-well plates or chamber slides and incubated for $24 \mathrm{~h}$ in the presence of $1 \mu \mathrm{g} / \mathrm{ml}$ LPS (Sigma-Aldrich), with or without, hAD-MSCs or EVs. To determine if there was any dose-dependent effects, HMC3 cells were kept consistent at 200,000 cells (with or without LPS stimulation) and the following groups tested: hAD-MSCs = 200,000, 100,000, and 50,000 cells and EVs $=50,20$, and $10 \mu \mathrm{g} / \mathrm{ml}$. Cocultures were live-imaged and analyzed using an Celigo image cytometer (Nexcelom, Lawrence, MA).

\section{XTT cell proliferation assay}

HMC3 cells were seeded in 96-well tissue culture plates containing complete growth medium EMEM (ATCC, VA, USA), supplemented with $10 \%$ fetal bovine serum (Gibco) and $1 \%$ penicillin/streptomycin (Gibco-Life Technologies, USA) and were cultured in the presence or absence of different doses of LPS $(0.1-10 \mu \mathrm{g} / \mathrm{ml})$. After treatments, cell viability was assessed using a XTT cell proliferation Cayman chemical assay kit (no. 10010200; Cayman Chemical). XTT reagent $(10 \mu \mathrm{l})$ was added to each well, which was subsequently incubated for $2 \mathrm{~h}$ at $37^{\circ} \mathrm{C}$. The culture medium was discarded, and $100 \mu \mathrm{l}$ of the crystal dissolving solution was added to dissolve the formazan dye. Then, absorbance was measured at $570 \mathrm{~nm}$ using a microplate spectrophotometer system (Tecan Infinite M200 plate reader). The obtained data were normalized to the absorbance value, measured obtained at $570 \mathrm{~nm}$ from nontreated cells $(100 \%)$, and expressed as a percentage of the control \pm standard error of the mean (SEM).

\section{ROS assay}

ROS were measured using $2^{\prime}, 7^{\prime}$-dichlorodihydrofluorescein diacetate (DCFH-DA) (D6883-50MG, sigma). DCFH-DA is a cell-permeable nonfluorescent probe which is hydrolyzed by intracellular esterases, thereby trapping it within the cell. This nonfluorescent molecule can then be oxidized by ROS, which then turns it into fluorescent dichlorofluorescin (DCF). The level of intracellular fluorescence is therefore proportional to the amount of intracellular ROS production with a linear dynamic range. All experiments were performed in 96well plates. HMC3 were incubated for 45 min with $10 \mu \mathrm{M}$ of DCFH-DA, and the fluorescence emission of DCF measured at $488 \mathrm{~nm}$ using a Celigo image cytometer (Nexcelom; Lawrence, MA).

\section{Phagocytosis assay}

To quantify the phagocytic capacity of HMC3, cells were grown in glass bottom chamber slides. After treatment, cells were incubated with $5 \mu \mathrm{l}$ of prelabeled zymosan particles (ab234054, Abcam) for $2 \mathrm{~h}$ and then washed by adding cold phagocytosis assay buffer. Cells were analyzed by confocal fluorescent microscopy (SP8 Leica microscope).

\section{Immunofluorescence staining}

Immunofluorescence staining was performed to detect the expression of microglia phenotype markers. Following 
Table 1 Antibody list.

\begin{tabular}{lllll}
\hline Name & Catalog number & Company & Host & Dilution \\
\hline Anti-CD63 & ab59479 & Abcam & Mouse & 1:1000 \\
Anti-CD11b & NB110-89474 & Novusbio & Rabbit & 1:1000 \\
Phalloidin- & 20555 & Cayman & N/A & N/A \\
iFluor ${ }^{\text {TM } 647}$ & & Chemical & & \\
Conjugate & & Company & & \\
Anti-iNOS & NBP2-22119SS & Novusbio & Mouse & 1:1000 \\
Anti-GAPDH & Sc-69778 & Santa Cruz & Mouse & $1: 1000$ \\
Anti-mouse HRP & 70765 & Cell Signaling & Horse & $1: 5000$ \\
Anti-rabbit 488 & A11008 & Thermo Fisher & Goat & $1: 500$ \\
& & Scientific & & \\
\hline
\end{tabular}

each experiment, HMC3 cells were washed with PBS, fixed with $4 \%$ formaldehyde for $30 \mathrm{~min}$ at room temperature, and permeabilized with $0.1 \%$ Triton X-100/PBS. Nonspecific staining was blocked with 5\% BSA in $0.1 \%$ Triton X-100/PBS for $1 \mathrm{~h}$ at room temperature. Cells were then incubated overnight at $4{ }^{\circ} \mathrm{C}$ with primary antibodies (Table 1). The next day, cells were rinsed with PBS, following which they were incubated with secondary antibodies (Table 1 ) for $1 \mathrm{~h}$ at room temperature. The nuclei were counterstained with DAPI for $5 \mathrm{~min}$ at room temperature. Stained samples were mounted using Vectashield fluorescence mounting media (Vector Laboratories Inc, Burlingame, CA, USA). Images were acquired with Leica SP8 inverted confocal microscope equipment (Leica Microsystems, IL, USA).

\section{Western blot analysis}

Samples were lysed with cold RIPA buffer (Pierce, Thermo Scientific) supplemented with a protease inhibitor mixture (Sigma-Aldrich). The protein concentration was determined using a $\mathrm{BCA}$ protein assay following the manufacturer's recommendations (Pierce, Thermo Scientific). For SDS-PAGE, samples were prepared in Laemmli buffer (Bio-Rad, Hercules, CA, USA), and $25 \mu \mathrm{g}$ of samples were loaded in $10-12 \%$ Mini-PROTEAN TGX ${ }^{\mathrm{TM}}$ gels (Bio$\mathrm{Rad})$ and transferred onto a nitrocellulose membrane. Membranes were blocked with $5 \%$ blotting-grade nonfat dry milk (Bio-Rad) in Tris-buffered saline (TBS) for $1 \mathrm{~h}$ at room temperature and incubated overnight at $4{ }^{\circ} \mathrm{C}$ with the indicated primary antibodies (Table 1 ) diluted in $0.1 \%$ TBS-Tween 20 (TBS-T). Membranes were washed with $0.1 \%$ TBS- $T$, incubated with the indicated secondary antibody (Table 1 ) for $1 \mathrm{~h}$ at room temperature, and then washed again with TBS-T. To create chemiluminescent signals, membranes were incubated with a ECL western blot substrate (GE Healthcare Ltd) and visualized on an IVIS Lumina imager, with Living Image Software.

\section{Cytokine assays}

Cytokine assays were performed using a Human Neuro Discovery Array C2 (RayBiotech, Norcross, GA, USA) according to the manufacturer's instructions. Membranes precoated with cytokine antibodies were blocked with a blocking buffer at room temperature for $30 \mathrm{~min}$; next, equal volumes of supernatants, collected from HMC3 cells treated, with or without $1 \mu \mathrm{g} / \mathrm{ml}$ LPS in the presence or absence of hADSCs or EVs, were added to replace the blocking buffer and incubated overnight at $4{ }^{\circ} \mathrm{C}$. After washing three times with wash buffer 1 and two times with wash buffer 2 , each membrane was incubated with biotin-conjugated antibodies for $2 \mathrm{~h}$ followed by a HRPconjugated streptavidin at room temperature for $30 \mathrm{~min}$. Membranes were developed by Detection buffer C and D mixture and the chemiluminescence was visualized by an IVIS Lumina-III In Vivo Imaging System (PerkinElmer). Densitometry analysis of the array was performed using the NIH Image J software.

\section{Statistical analysis}

All data are expressed as means \pm SEM. Two-tailed Student's $t$ tests were applied to assess differences. For all assays (three repetitions, regardless of intra-assay triplicates) were evaluated by the corresponding statistical test. $P$ values of $<0.05$ were considered significant.

\section{Author contributions}

MGC and AST conceived the project. and. designed the experiments, analyzed the data, and revised the manuscript. MGC performed the experiments, wrote the manuscript, in part, and analyzed the data.

\section{Funding}

This work was supported by the Radiology Research Fund for Alzheimer's disease at Stanford University.

\section{Conflict of interest}

The authors declare no competing interests.

\section{Ethical statement}

This research does not involve human subjects nor use animals. The origin of all the cell lines is indicated in Material and Methods.

\section{Publisher's note}

Springer Nature remains neutral with regard to jurisdictional claims in published maps and institutional affiliations.

Supplementary information The online version contains supplementary material available at https://doi.org/10.1038/s41420-021-00471-7.

Received: 23 November 2020 Revised: 5 February 2021 Accepted: 7 April 2021

Published online: 10 May 2021

\footnotetext{
References

1. Smith, A. M. \& Dragunow, M. The human side of microglia. Trends Neurosci. 37, 125-135 (2014).

2. Ransohoff, R. M. \& Cardona, A. E. The myeloid cells of the central nervous system parenchyma. Nature 468, 253-262 (2010).
} 
3. Hansen, D. V., Hanson, J. E. \& Sheng, M. Microglia in Alzheimer's disease. J. Cell Biol. 217, 459-472 (2018).

4. Keren-Shaul, $H$. et al. A unique microglia type associated with restricting development of Alzheimer's disease. Cell 169, 1276-1290 (2017).

5. Verheijen, J. \& Sleegers, K. Understanding Alzheimer disease at the interface between genetics and transcriptomics. Trends Genet. 34, 434-447 (2018).

6. Sheng, $H$. et al. A critical role of IFNgamma in priming MSC-mediated suppression of $\mathrm{T}$ cell proliferation through up-regulation of B7-H1. Cell Res. 18, 846-857 (2008)

7. Yeung, T. Y. et al. Human mesenchymal stem cells protect human islets from pro-inflammatory cytokines. PLOS ONE 7, e38189 (2012).

8. Duffy, M. M. et al. Mesenchymal stem cell inhibition of T-helper 17 celldifferentiation is triggered by cell-cell contact and mediated by prostaglandin E2 via the EP4 receptor. Eur. J. Immunol. 41, 2840-2851 (2011).

9. Aggarwal, S. \& Pittenger, M. F. Human mesenchymal stem cells modulate allogeneic immune cell responses. Blood 105, 1815-1822 (2005).

10. Cosenza, S. et al. Mesenchymal stem cells-derived exosomes are more immunosuppressive than microparticles in inflammatory arthritis. Theranostics 8, 1399-1410 (2018).

11. Hu, Y. et al. Upregulated TSG-6 expression in ADSCs inhibits the BV2 microgliamediated inflammatory response. Biomed. Res. Int. 2018, 7239181 (2018).

12. Di Nicola, M. et al. Human bone marrow stromal cells suppress T-lymphocyte proliferation induced by cellular or nonspecific mitogenic stimuli. Blood 99, 3838-3843 (2002).

13. Corcione, A. et al. Human mesenchymal stem cells modulate B-cell functions. Blood 107, 367-372 (2006).

14. Le Blanc, K. Immunomodulatory effects of fetal and adult mesenchymal stem cells. Cytotherapy 5, 485-489 (2003).

15. Miana, V. V. \& Gonzalez, E. A. P. Adipose tissue stem cells in regenerative medicine. Ecancermedicalscience 12, 822 (2018).

16. Ma, T. et al. Intracerebral transplantation of adipose-derived mesenchymal stem cells alternatively activates microglia and ameliorates neuropathological deficits in Alzheimer's disease mice. Cell Transplant. 22(Suppl 1), S113-S126 (2013).

17. Nasiri, E. et al. Melatonin-pretreated adipose-derived mesenchymal stem cells efficeintly improved learning, memory, and cognition in an animal model of Alzheimer's disease. Metab. Brain Dis. 34, 1131-1143 (2019).

18. Tsolaki, M., Zygouris, S., Tsoutsikas, V., Anestakis, D. \& Koliakos, G. G. Treatment with adipose stem cells in a patient with moderate Alzheimer's disease: case report. J. Neurorestoratol. 3, 115-120 (2015).

19. Marfia, G. et al. The adipose mesenchymal stem cell secretome inhibits inflammatory responses of microglia: evidence for an involvement of sphingosine-1-phosphate signalling. Stem Cells Dev. 25, 1095-1107 (2016).

20. Farinazzo, A. et al. Nanovesicles from adipose-derived mesenchymal stem cells inhibit $T$ lymphocyte trafficking and ameliorate chronic experimental autoimmune encephalomyelitis. Sci. Rep. 8, 7473 (2018).

21. Thery, C., Zitvogel, L. \& Amigorena, S. Exosomes: composition, biogenesis and function. Nat. Rev. Immunol. 2, 569-579 (2002).

22. Valadi, $H$. et al. Exosome-mediated transfer of mRNAs and microRNAs is a novel mechanism of genetic exchange between cells. Nat. Cell Biol. 9, 654-U672 (2007).

23. Li, Y. et al. Exosomes secreted by stem cells from human exfoliated deciduous teeth contribute to functional recovery after traumatic brain injury by shifting microglia M1/M2 polarization in rats. Stem Cell Res. Ther. 8, 198 (2017).

24. Rani, S., Ryan, A. E., Griffin, M. D. \& Ritter, T. Mesenchymal stem cell-derived extracellular vesicles: toward cell-free therapeutic applications. Mol. Ther.: J. Am. Soc. Gene Ther. 23, 812-823 (2015).

25. Zhu, X. et al. Comprehensive toxicity and immunogenicity studies reveal minimal effects in mice following sustained dosing of extracellular vesicles derived from HEK293T cells. J. Extracell. Vesicles 6, 1324730 (2017).

26. Seok, J. et al. Genomic responses in mouse models poorly mimic human inflammatory diseases. Proc. Natl Acad. Sci. USA 110, 3507-3512 (2013).

27. Fernandes, A. et al. Secretome from SH-SY5Y APP(Swe) cells trigger timedependent CHME3 microglia activation phenotypes, ultimately leading to miR-21 exosome shuttling. Biochimie 155, 67-82 (2018).

28. Dello Russo, C. et al. The human microglial HMC3 cell line: where do we stand? A systematic literature review. J. Neuroinflammation 15, 259 (2018).

29. Vezzani, B. et al. Higher pericyte content and secretory activity of microfragmented human adipose tissue compared to enzymatically derived stromal vascular fraction. Stem Cells Transl. Med. 7, 876-886 (2018).
30. Ooi, Y. Y. et al. Bone marrow-derived mesenchymal stem cells modulate BV2 microglia responses to lipopolysaccharide. Int. Immunopharmacol. 10, 1532-1540 (2010).

31. Liu, Y. et al. Mesenchymal stem cells inhibit lipopolysaccharide-induced inflammatory responses of BV2 microglial cells through TSG-6. J. Neuroinflammation 11, 135 (2014).

32. Galipeau, J. \& Sensebe, L. Mesenchymal stromal cells: clinical challenges and therapeutic opportunities. Cell Stem Cell 22, 824-833 (2018).

33. Orbay, H., Tobita, M. \& Mizuno H. Mesenchymal stem cells isolated from adipose and other tissues: basic biological properties and clinical applications. Stem Cells Int. 2012, 461718 (2012).

34. Scopetti, M. et al. Mesenchymal stem cells in neurodegenerative diseases: Opinion review on ethical dilemmas. World J. Stem Cells 12, 168-177 (2020).

35. Shahror, R. A., Ali, A. A. A., Wu, C. C., Chiang, Y. H. \& Chen, K. Y. Enhanced homing of mesenchymal stem cells overexpressing fibroblast growth factor 21 to injury site in a mouse model of traumatic brain injury. Int. J. Mol. Sci. 20 (2019).

36. Petrenko, Y. et al. A comparative analysis of multipotent mesenchymal stromal cells derived from different sources, with a focus on neuroregenerative potential. Sci. Rep. 10, 4290 (2020).

37. Saldana, L. et al. Paracrine interactions between mesenchymal stem cells and macrophages are regulated by 1,25-dihydroxyvitamin D3. Sci. Rep. 7, 14618 (2017).

38. Sun, D. Z., Abelson, B., Babbar, P. \& Damaser, M. S. Harnessing the mesenchymal stem cell secretome for regenerative urology. Nat. Rev. Urol. 16, 363-375 (2019).

39. Hur, Y. H., Cerione, R. A. \& Antonyak, M. A. Extracellular vesicles and their roles in stem cell biology. Stem Cells 38, 469-476 (2020).

40. Mendt, M., Rezvani, K. \& Shpall, E. Mesenchymal stem cell-derived exosomes for clinical use. Bone Marrow Transplant. 54(Suppl 2), 789-792 (2019).

41. Long, Q. et al. Intranasal MSC-derived A1-exosomes ease inflammation, and prevent abnormal neurogenesis and memory dysfunction after status epilepticus. Proc. Natl Acad. Sci. USA 114, E3536-E3545 (2017).

42. Chen, S. et al. TLR4 signaling pathway mediates the LPS/ischemia-induced expression of monocytechemotactic protein-induced protein 1 in microglia. Neurosci. Lett. 686, 33-40 (2018).

43. Qin, Y. et al. Stimulation of TLR4 sttenuates Alzheimer's disease-related symptoms and pathology in tau-transgenic mice. J. Immunol. 197, 3281-3292 (2016).

44. Liu, J. F., Wu, R. \& Li, J. X. Toll of mental disorders: TLR-mediated function of the innate immune system. Neurosci. Bull. 35, 771-774 (2019).

45. Possel, H., Noack, H., Putzke, J., Wolf, G. \& Sies, H. Selective upregulation of inducible nitric oxide synthase (iNOS) by lipopolysaccharide (LPS) and cytokines in microglia: in vitro and in vivo studies. Glia 32, 51-59 (2000).

46. Brown, G. C. Mechanisms of inflammatory neurodegeneration: iNOS and NADPH oxidase. Biochem. Soc. Trans. 35, 1119-1121 (2007).

47. Ehrlich, L. C. et al. Cytokine regulation of human microglial cell IL-8 production. J. Immunol. 160, 1944-1948 (1998).

48. Yuan, B. et al. MCP-1-mediated activation of microglia promotes white matter lesions and cognitive deficits by chronic cerebral hypoperfusion in mice. Mol. Cell Neurosci. 78, 52-58 (2017).

49. Magni, P. et al. Parthenolide inhibits the LPS-induced secretion of IL-6 and TNF-alpha and NF-kappaB nuclear translocation in BV-2 microglia. Phytother. Res. 26, 1405-1409 (2012).

50. Lee, Y. B., Nagai, A. \& Kim, S. U. Cytokines, chemokines, and cytokine receptors in human microglia. J. Neurosci. Res. 69, 94-103 (2002).

51. Gabay, C. Interleukin-6 and chronic inflammation. Arthritis Res. Ther. 8(Suppl 2), S3 (2006)

52. Zoubovsky, S. P. et al. Working memory deficits in neuronal nitric oxide synthase knockout mice: potential impairments in prefrontal cortex mediated cognitive function. Biochem. Biophys. Res. Commun. 408, 702-712 (2011).

53. Maher, A. et al. Overexpression of NMDAR2B in an inflammatory model of Alzheimer's disease: modulation by NOS inhibitors. Brain Res. Bull. 109, 109-116 (2014).

54. Nathan, $\mathrm{C}$. et al. Protection from Alzheimer's-like disease in the mouse by genetic ablation of inducible nitric oxide synthase. J. Exp. Med. 202, 1163-1169 (2005).

55. Zhang, P. et al. Tissue inhibitor of matrix metalloproteinases-1 knockdown suppresses the proliferation of human adipose-derived stem cells. Stem cells Int. 2016, 4761507 (2016). 
56. Egea, V. et al. Tissue inhibitor of metalloproteinase-1 (TIMP-1) regulates mesenchymal stem cells through let-7f microRNA and Wnt/beta-catenin signaling. Proc. Natl Acad. Sci. USA 109, E309-E316 (2012).

57. Jiang, Y. et al. Multipotent progenitor cells can be isolated from postnatal murine bone marrow, muscle, and brain. Exp. Hematol. 30, 896-904 (2002).

58. Zhang, S. et al. Interleukin 6 mediates the therapeutic effects of adiposederived stromal/stem cells in lipopolysaccharide-induced acute lung injury. Stem Cells 32, 1616-1628 (2014).

59. Meng, J. et al. The critical role of IL-10 in the antineuroinflammatory and antioxidative effects of rheum tanguticum on activated microglia. Oxid. Med Cell Longev. 2018, 1083596 (2018).

60. Asselineau, D. et al. Interleukin-10 production in response to amyloid-beta differs between slow and fast decliners in patients with Alzheimer's disease. J. Alzheimers Dis. 46, 837-842 (2015).

61. Nuttall, R. K. et al. Metalloproteinases are enriched in microglia compared with leukocytes and they regulate cytokine levels in activated microglia. Glia $\mathbf{5 5}$ 516-526 (2007).

62. Knight, B. E. et al. TIMP-1 attenuates the development of inflammatory pain through MMP-dependent and receptor-mediated cell signaling mechanisms. Front. Mol. Neurosci. 12, 220 (2019).
63. Popiolek-Barczyk, K. et al. Parthenolide relieves pain and promotes $M 2$ microglia/macrophage polarization in rat model of neuropathy. Neural Plast. 2015, 676473 (2015).

64. Zhang, $X$. et al. Positive feedback loop of autocrine BDNF from microglia causes prolonged microglia activation. Cell Physiol. Biochem. 34, 715-723 (2014).

65. Ferrini, F. \& De Koninck, Y. Microglia control neuronal network excitability via BDNF signalling. Neural Plast. 2013, 429815 (2013).

66. Beeri, M. S. \& Sonnen, J. Brain BDNF expression as a biomarker for cognitive reserve against Alzheimer disease progression. Neurology 86, 702-703 (2016).

67. Alvarez, X. A. et al. Synergistic increase of serum BDNF in Alzheimer patients treated with cerebrolysin and donepezil: association with cognitive improvement in ApoE4 cases. Int. J. Neuropsychopharmacol. 19, pyw024 (2016).

68. Bianchi, F. et al. A new nonenzymatic method and device to obtain a fat tissue derivative highly enriched in pericyte-like elements by mild mechanical forces from human lipoaspirates. Cell Transplant. 22, 2063-2077 (2013).

69. García-Contreras, M. M. F., Jimenez, O. \& Mendez, A. Differences in exosome content of human adipose tissue processed by non-enzymatic and enzymatic methods. CellR4 3, e1423 (2015). 